\title{
“LII" REUNION ANUAL DEL PROGRAMA COOPERATIVO CENTROAMERICANO PARA EL MEJORAMIENTO DE CULTIVOS Y ANIMALES (PCCMCA)
}

\author{
ACTA DE LA QUINCEAVA ASAMBLEA GENERAL DE LA SOCIEDAD DEL \\ PROGRAMA COOPERATIVO CENTROAMERICANO PARA EL MEJORAMIENTO \\ DE CULTIVOS Y ANIMALES (PCCMCA), CELEBRADA EL DÍA 28 DE ABRIL DEL \\ 2006, EN EL HOTEL BARCELÓ MONTELIMAR, EN MANAGUA, NICARAGUA
}

\section{INTRODUCCIÓN}

\section{DESARROLLO DE LA ASAMBLEA}

El día 28 de abril del 2006 a las 2:30 pm se instaló la mesa principal conformada por:

Dr. Noel E. Pallais -Nicaragua

Lic. José Antonio Rivera -Nicaragua

Dra. Carmen Bieberach (IDIAP - Panamá

Ing. Mario Roberto Fuentes - ICTA Guatemala

Lic. Francisco Enciso - SICTA

Se dio inicio a la Asamblea y se propuso la agenda a desarrollar:

1) Revisión del Quórum

2) Conclusiones y premiación de trabajos por mesas.

- Leguminosas

- Maíz

- Arroz y Sorgo

- Hortalizas, Frutales, Raíces y Tubérculos

- Producción Animal y Pastos

- Socioeconomía y Extensión

- Biotecnología y Recursos Naturales

- Posters

3) Propuesta de reforma a los Estatutos del PCCMCA

4) Nombramiento de los editores asociados y Consejo Editorial
5) Propuestas para gestionar apoyo y participación de la Red SICTA en la Revista Agronomía Mesoamericana y en las Reuniones Anuales del PCCMCA.

6) Elección de Nueva Sede de la Reunión Anual del PCCMCA- 2007

7) Asuntos varios

8) Clausura

1. Se verificó el Quórum

2. CONCLUSIONES POR MESA DE TRABAJO

\section{MESA DE LEGUMINOSAS}

La mesa de leguminosas agradece al gobierno de Nicaragua por su hospitalidad en la realización del evento y al Instituto Nicaragüense de Tecnología Agropecuaria (INTA) de Nicaragua.

\section{Directiva de la Mesa}

Presidente: Ing. Aurelio Llano - Nicaragua Secretario: Ing. Julio César Villatoro-Guatemala Moderador: Ing. Ernesto López Salinas-México

En la mesa de leguminosas se presentaron 35 ponencias, en las áreas de mejoramiento genético, transferencias, manejo agronómico. 


\section{Número de trabajos programados y presenta- dos}

a) Total programados: 33

b) Total presentados: 31

c) Porcentaje de participación $95 \%$

d) Por área o disciplina

- Mejoramiento genético: 17

- Transferencias: 10

- Manejo agronómico: 5

- Recursos genéticos: 3

e) Por género de expositores: mujeres (2), hombres (29)

\section{Número de participantes en la mesa}

Primer día: 28 personas

Segundo día: 32 personas

Tercer día: 33 personas

TOTAL: 93 PROMEDIO: 31 personas por día

\section{Lista de países representados}

Nicaragua: 9

México: 6

Honduras: 5

Colombia: 3

Cuba: 1

Guatemala: 1

El Salvador: 1

Costa Rica: 2

\section{Trabajos ganadores}

Primer lugar (15 puntos): Atlas de frijol de América. Ing.Orlando Mejía - Honduras, Escuela Agrícola Panamericana de El Zamorano.

Segundo Lugar (14 puntos): Modificación del contenido de oligosácaridos en frijol común. Carmen Jacinto Hernández - México

Tercer lugar (13 puntos): Fitomejoramiento Participativo en frijol, Nicaragua. Validación de tres líneas de frijol en 16 localidades de Las Segovias. Rolando Herrera - Nicaragua.

Tercer Lugar (13 puntos): Fitomejoramiento Participativo en frijol. Organización de productores de
El Águila, región Brunca, Costa Rica. Rolando Cubero - Costa Rica.

\section{Resultados relevantes}

Todos los trabajos presentados fueron sobre frijol de grano rojo y negro.

En mejoramiento genético se evaluaron los viveros regionales del SISTEVER en los diferentes países. Los programas nacionales identificaron los genotipos más eficientes y se apropiaron del nuevo germoplasma. Los productores de frijol rojo disponen de nuevas variedades con buenas características para el mercado local y promover las exportaciones al mercado regional, gracias al flujo de nuevo germoplasma. En frijol negro se han identificado nuevos genotipos con buenas características agronómicas y de rendimiento, pero los países que consumen este grano no han liberado nuevas variedades.

Se presentaron los resultados de validación, difusión y liberación de variedades rojas con calidad de grano y rendimiento superiores a las variedades comerciales disponibles. Se debe promover el trabajo de transferencia y adopción para la producción de mayores volúmenes de alimentos. En el Salvador se busca la adaptación a baja altitud y alta temperatura.

En mejoramiento para factores abióticos se han incrementado con trabajos en baja fertilidad y sequía. En sequía se han identificado y validado genotipos más eficientes para zonas con baja precipitación que deben complementarse con prácticas de manejo para conservar la humedad. Se han identificado fuentes para baja fertilidad, que deben incorporarse a las variedades comerciales.

Se presentaron resultados de las causas de la inestabilidad del color de grano rojo con el tiempo de almacenamiento, estudios que deben continuarse para reducir las pérdidas de calidad.

Especial interés existe en la región por la colecta, identificación y caracterización de las especies nativas y cultivadas de Phaseolus, para evitar la erosión genética de estos cultivares y disponer de fuentes de variación en el futuro. Se presentaron los resultados de la caracterización realizadas en Guatemala y México. 


\section{Recomendaciones}

Continuar con las evaluaciones del SISTEVER.

Incrementar la selección de líneas promisorias de frijol negro en Costa Rica.

\section{MESA DE MAÍZ}

La mesa de maíz durante la LII Reunión del PCCMCA 2006 estuvo conformada por Investigadores de Programas Nacionales, Sector Privado y representantes de organizaciones a nivel regional.

\section{Directiva de la Mesa}

Presidente: Ing. Alberto Espinoza - Nicaragua Secretario: Ing. Mario Roberto Fuentes-Guatemala Moderadores: Ing. Oscar Cruz-Honduras y Dr. Gustavo Velásquez - México.

Agradecimiento al pueblo y gobierno de Nicaragua por la cálida recepción que se ha tenido a las diferentes delegaciones de los países participantes. Así mismo, a los Programas Regionales, Centros Internacionales y Sector Privado que apoyaron la participación de los diferentes investigadores a esta reunión.

\section{Número de trabajos programados y presentados}

a) Total ponencias presentadas: 41

b) Total pósters: 7

Por área o disciplina

- Mejoramiento genético

- Manejo agronómico

- Protección de Cultivos

- Manejo postcosecha

- Producción de semilla

- Nutrición humana con alta calidad de proteína y biofortificación.

\section{Comité calificador}

Ing. Humberto Blandón - Nicaragua

Ing. José Luis Torres- México

Dr. Mauro Sierra - México

Ing. Hector Deras - El Salvador

Dr. Elio Durón - Honduras

\section{Trabajos ganadores}

Primer lugar: Efecto de la ingesta de maíz de alta calidad de proteína vs maíz normal en el crecimiento y desarrollo en niños con edades entre uno y cinco años. Eveling Ortega, Adrián Coulson y Lastenia Ordóñez asesorados por: Alberto Espinoza - Nicaragua.

Segundo lugar: Colección, evaluación, caracterización agronómica y molecular con microsatélites (SRR) de germoplasma de maíz con tolerancia a sequía. Silvana Maselli de Sánchez, Mario Roberto Fuentes y José Luis Zea Morales - ICTA, Guatemala.

Tercer lugar: Manejo de la Fertilización Suplementaria y el Efecto de dos Mejoradores del Suelo en el cultivo de Maíz en Azuero, Panamá. Román Gordón - IDIAP Panamá.

\section{Conclusión}

Es evidente el progreso en el desarrollo de híbridos y variedades de maíz de alta calidad de proteína y consistente respuesta del rendimiento a ambientes contrastantes, superando significativamente a testigos locales en características agronómicas sobresalientes tales como menor pudrición de la mazorca, resistencia a enfermedades foliares y adaptabilidad en el rendimiento de grano.

El estudio nutricional en el uso de grano de maíz QPM en niños con edades entre uno y cinco años, realizado en Nicaragua, demuestra efectivamente la contribución de los cultivares de maíz QPM en reducir la desnutrición.

Fortalecer la cooperación y alianzas interinstitucionales entre sector público y privado, universidades, industria de alimentos para eficientar el uso y difusión del grano de maíz QPM en los procesos alimentarios.

Se analizó la problemática del intercambio de germoplasma entre los diferentes países a consecuencia del endurecimiento de los trámites administrativos en aduana por parte de las oficinas de normas y regulaciones en cada uno de los países. Esta situación ha ocasionado atrasos y en varios casos la pérdida de valioso germoplasma con implicaciones en el avance en los procesos de investigación. 


\section{Recomendaciones}

1) Se solicita a los autores de los mejores trabajos presentados en la Mesa de Maíz, proceder a su divulgación en la Revista Mesoamericana.

2) Enfatizar en el manejo agronómico para materiales élite de maíz QPM, antes de su liberación comercial.

3) Aprovechar la información en los estudios de nutrición en niños para convencer a los tomadores de decisiones (ministros, políticos, alcaldes, etc) que apoyen el uso de esta alternativa tecnológica.

4) Realizar estudios nutricionales en humanos y animales en otros países de influencia del PCCMCA para valorar la importancia del QPM en la nutrición humana.

5) Darle seguimiento, aplicación y cumplimiento a las conclusiones y recomendaciones emanadas de esta reunión.

6) Solicitar al próximo país organizador de la LIII Reunión del PCCMCA del 2007 dedicar el evento en honor al Dr. Hugo Salvador Córdova, por su valioso y significativo aporte a la Ciencia y Tecnología Agropecuaria en la Región. El Dr. Córdova está en proceso de retiro del CIMMYT.

\section{MESA DE ARROZ Y SORGO}

\section{Directiva de la Mesa}

El Ing. Rafael Obando por designación del Comité Organizador dio la bienvenida a los participantes presentes a la mesa de Arroz y Sorgo, acto seguido se procedió a la selección de las Juntas Directivas por cultivo, quedando integrado por las siguientes personas:

\section{Mesa de Arroz:}

Presidente: Dr. Lázaro Narváez - Nicaragua Secretario: Ing. Luís Alberto Guerrero - El Salvador Moderador: Dr. Bernardo Mora - Costa Rica

\section{Comité calificador de arroz:}

Dr. César Martínez: CIAT, Colombia. Ing. Leopoldo Serrano: El Salvador.

Ing. Angel Adames: República Dominicana.

\section{Mesa de Sorgo:}

Presidente: Ing. Rafael Obando - Nicaragua

Secretario: Ing. Juan Catalán - Guatemala

Moderador: Ing. René Clara - El Salvador

\section{Comité calificador de sorgo}

Ing. Reina Flor Guzmán. El Salvador Dr. Gilles Trouche: CIAT, Colombia. Ing. Wilfredo Castañeda: El Salvador

\section{Desarrollo de las presentaciones}

La mesa de arroz y sorgo contó con una asistencia de 33 participantes.

Primer día: 24

Segundo día: 40

Tercer día: 30

El número de trabajos presentados fue de 46 :

- Arroz: 18 en total, mujeres 3 y hombres 15.

- Sorgo: 28 en total, 23 hombres y 5 mujeres.

Las disciplinas presentadas en la mesa fueron:

\begin{tabular}{llrr}
\hline No. & \multicolumn{1}{c}{ Disciplina } & Arroz & Sorgo \\
\hline & Mejoramiento genético & 13 & 13 \\
2 & Agronomía & 1 & 11 \\
3 & Protección vegetal & 3 & 2 \\
4 & Investigación industrial & & 2 \\
5 & Biofortificación & 1 & \\
\hline
\end{tabular}

III. Los países expositores fueron: Guatemala, Honduras, El Salvador, Nicaragua, Costa Rica, Panamá, Cuba, República Dominicana, Colombia, USA. 


\section{Trabajos ganadores}

\section{Mesa de Arroz}

Primer lugar (42 puntos): Dinámica poblacional de ácaro Steneotarsonemus spinki, en diferentes épocas de siembra y épocas fonológicas en dos variedades de arroz. IDIAP, Panamá.2004-2005. Evelyn Quiroz - Panamá.

Segundo lugar (42 puntos): Evaluación de tres variedades de arroz y su productividad con el uso de soca en transplante en República Dominicana. Angel Adames - República Dominicana.

Tercer lugar (40 puntos): Identificación de cultivos con adaptación amplia y específica bajo condiciones de secado favorecido utilizando el análisis AMMI y el BIPLOT ggesreg. IDIAP, Panamá. Ismael Camargo - Panamá.

\section{Mesa de Sorgo}

Primer lugar: Desarrollo de variedades de híbridos de sorgo (Sorghum bicolor L. Moench) con alta calidad de grano y adaptadas a diferentes ambientes agroclimáticos de El Salvador. Humberto Salvador Zeledón - El Salvador.

Segundo lugar: Alternativas tecnológicas para la producción de harina de sorgo en la industria panificadora. Eliette Palacio - Nicaragua.

Tercer lugar: Evaluación de productos para el manejo de insectos, plagas y enfermedades de sorgo. Martha Zamora - Nicaragua.

\section{Conclusiones}

Establecer una mayor comunicación entre instituciones de investigación de la región, a fin de divulgar los resultados de investigación.

Se debe aumentar el número de localidades donde se efectúen las evaluaciones y/o validación, a fin de aumentar la confiabilidad de los resultados.

Cuando se presenten resultados de evaluación de germoplasma se utilicen los códigos o nombres de origen, a fin de facilitar la identificación de los genotipos para su uso potencial en los programas de mejora genética.

\section{Recomendaciones}

Definir con más claridad las normas de propiedad intelectual de los genotipos intercambiados.

Se considera de importancia para la región mejorar la capacidad técnico-científico de los investigadores tanto, para las disciplinas convencionales de manejo de los cultivos y de tecnologías para la transformación de los productos. El objetivo es lograr un mayor valor agregado y mejorar el valor nutricional de los mismos.

\section{Agradecimientos}

Los participantes de la mesa de arroz y sorgo expresan sus agradecimientos a los organizadores de la LII Reunión Anual del PCCMCA, al INTA y a todos los organismos nacionales e internacionales, al pueblo y gobierno de Nicaragua que han contribuido al desarrollo del evento con sus atenciones brindadas.

\section{MESA DE HORTALIZAS, FRUTALES, RAÍCES Y TUBÉRCULOS}

\section{Directiva de la mesa}

Presidente: Ing. Tomás Laguna - Nicaragua

Secretario: Ing. Osman Cifuentes-Guatemala

Moderador: Ing. Juan de Dios Molina-Nicaragua

\section{Número de trabajos programados y presentados}

Total programados: 58

Total presentados: 49

Porcentaje de participación $85 \%$

Participación por cultivo: 29 cultivos

Por área o disciplina

Mejoramiento genético: $15=31 \%$

Manejo integrado de plagas: $12=24 \%$

Manejo agronómico: 19=39\%

Biotecnología: $2=4 \%$

Agroindustria: $1=2 \%$

Por género de expositores:

mujeres $(3 \%)$

hombres $(97 \%)$ 


\section{Número de participantes en la mesa}

Primer día: 31 personas

Segundo día: 36 personas

Tercer día: 51 personas

Total: 118 Promedio: 39 personas por día

\section{Países representados}

Nicaragua (19), México (5), Puerto Rico (1), Honduras (1), Guatemala (7), Estados Unidos (4), El Salvador (4), Panamá (1), Costa Rica (7).

\section{Trabajos ganadores}

Primer lugar (41 puntos): Evaluación de la resistencia al virus X de la papa, de 25 accesiones de Solanum L. sección Petota Dumort nativas de Guatemala. Freddy Rosales Longo - Guatemala/ ICTA.

Segundo lugar (39 puntos): Evaluación y selección de variedades de tomate con alto contenido de Beta-Caroteno en el valle de Sébaco, Matagalpa, Nicaragua. Tomás Javier González - Nicaragua - INTA.

Tercer lugar (38 puntos): Efecto de policultivo (tomate:Licopersicum esculentum, Pipián: Cucurbita pepo, frijol: Phaseolus vulgaris), en la incidencia poblacional de insectos plagas e insectos benéficos. Víctor Manuel Sandino - Nicaragua / UNA.

\section{Conclusiones y Recomendaciones}

Se alcanzó un alto porcentaje del 85\% de cumplimiento con respecto a los trabajos programados.

Hubo una baja considerable en la participación de la mujer en los trabajos presentados.

Se pudo observar una alta presentación en diversificación de cultivos.

Expositores de nueve países de la región realizaron exposiciones en la mesa de hortalizas.
Utilizar y uniformizar correctamente las abreviaturas empleadas.

Uniformizar en lo posible las variables o rangos empleados en la medición de las calidades o calibres de los resultados.

Al realizar los análisis estadísticos no utilizar el valor absoluto de las medias, para otros análisis.

Aumentar los trabajos de investigación en temas MIP, Biotecnología y Agroindustria.

Procurar encontrar los mecanismos para trasladar la información a los productores.

Generar proyectos en red a través de toda la región, aprovechando los recursos de SICTA y las facilidades del correo electrónico.

Para próximos eventos del PCCMCA delimitar el contenido de las diapositivas de las presentaciones. Las diapositivas deben presentar letras más grandes.

Promover la participación de la mujer en trabajos de investigación en hortalizas, frutales, raíces y tubérculos.

Cuando se realicen trabajos de investigación de una misma temática en diferentes localidades, consolidarlo en un mismo informe, realizando análisis combinado.

\section{MESA PRODUCCIÓN ANIMAL Y PASTOS}

\section{Directiva de la Mesa:}

Presidente: Ing. Alejandro César Blandón Gadea INTA/ Nicaragua

Secretario: Lic. Benigno Guerrero Rojas IDIAP / Panamá

Moderador y Vocal: Ing. Martín Mena, INTA / Nicaragua

\section{Número de trabajos presentados: 21.}




\begin{tabular}{|l|c|c|c|c|c|}
\hline & Bovinos & Ovinos & Cerdos & Otros & Total \\
\hline Pasturas & 3 & & & & 3 \\
\hline Bancos forrajeros & 6 & 1 & 1 & & 8 \\
\hline Estudios diagnósticos & 2 & & & & 2 \\
\hline Uso residuos orgánicos & & 2 & & & 2 \\
\hline Nutrición animal & & & 1 & & 1 \\
\hline Sanidad animal & & & & 1 & 1 \\
\hline $\begin{array}{l}\text { Producción de forrajes } \\
\text { hidropónicos }\end{array}$ & & & & 1 & 1 \\
\hline $\begin{array}{l}\text { Manejo de residuos orgá- } \\
\text { nicos provenientes de la } \\
\text { actividad pecuniaria }\end{array}$ & & & & 1 & 1 \\
\hline $\begin{array}{l}\text { Metodologías para } \\
\text { determinar la calidad } \\
\text { de alimentos }\end{array}$ & & & & 2 & 2 \\
\hline Total & 11 & 3 & 2 & 5 & 21 \\
\hline
\end{tabular}

\section{Género de expositores}

Mujeres: 0

Hombres: 21

\section{Número de participantes en la Mesa}

Día 1: 22

Día 2: 18

Día 3: 0 (El programa de la mesa se cumplió en dos días)

\section{Países representados}

Puerto Rico, Honduras, Panamá, Nicaragua, México, Costa Rica

\section{Trabajos ganadores}

Primer lugar: Efectos de la suplementación de la vaca lechera con diferentes niveles de moringa oleífera sobre el consumo digestibilidad, producción y composición de la leche. Nadir Reyes Sánchez - Nicaragua

Segundo lugar: Evaluación del uso de Moringa oleifera en dieta de cerdos de engordes y su efecto sobre parámetros productivos y calidad de la canal. Bryan Mendieta Araica. UNA / Nicaragua

Tercer lugar: Aporte del centro de estudio, diagnóstico e investigación veterinaria (C.E.D.I.V.E.), de la Facultad de Ciencias Agrarias Universidad de Ciencias
Comerciales (UCC) al conocimiento de la salud animal en Nicaragua. Enrique Rimbaud - Nicaragua

\section{Conclusiones}

Con base en los trabajos presentados en la mesa de producción animal, se concluyó que las especies de animales en que hubo mayor investigación fueron bovinos, ovinos y cerdos.

La disciplina de mayor participación fue la producción de bancos forrajeros y pasturas mejoradas, lo que muestra una tendencia hacia la intensificación de la producción pecuniaria.

El alto porcentaje de trabajos, tanto de forrajes de corte y de piso, permite concluir que en la mayoría de los países participantes se tiene como limitante la alimentación en las actividades pecuniarias.

La mayoría de los trabajos presentados tienen muchas posibilidades de aplicación y adopción por parte de los productores.

\section{Recomendaciones}

Se sugiere a los científicos que los futuros trabajos de investigación y validación de gramíneas se incorpore el componente de leguminosas.

Motivar la gestión de recursos a nivel de región para realizar investigación y validación de interés común.

En futuros trabajos de evaluación de pasturas y forrajes, considerar además de la evaluación agronómica, la respuesta animal y su factibilidad bioeconómica y ambiental.

Orientar las investigaciones y validaciones de manejo integrado de fincas con una mayor participación de los productores empresarios.

\section{MESA DE SOCIOECONOMÍA Y EXTENSIÓN}

\section{Directiva de la Mesa}

Presidente: Lic. Lesbia Rizo - Nicaragua (INTA) 
Vice-presidente: Ing. Claudia Calderón - Guatemala (ICTA)

Secretaria: Ing. Ana Lucía Lorío- Nicaragua (INTA)

Moderador: Ing. Alejandro Sequeira- Nicaragua (INTA)

En esta mesa de trabajo los miembros fungieron como jurado calificador.

\section{Número de trabajos presentados}

Total presentados: 19

Por área o disciplina

- Adopción de tecnologías

- Metodologías de extensión

\section{Países representados}

Nicaragua, México, Honduras, El Salvador, Costa Rica, Perú.

\section{Trabajos ganadores}

Primer lugar: Organización, regulación y tecnología para el manejo y conservación del recurso hídrico en la microcuenca del río de aguas calientes, Nicaragua. Ana Lorío - Nicaragua/ INTA.

Segundo lugar: Factores que intervienen en los programas de extensión agropecuaria institucional. María Elena Murillo - México.

Tercer lugar: Estrategia de desarrollo para la microcuenca pata de gallina. Imara Mejía - Nicaragua/ INTA.

\section{Conclusión}

Hubo baja calidad técnica y metodológica en los trabajos presentados en esta mesa.

\section{Recomendaciones}

Se recomienda a los países sedes del congreso, poner más atención a la calidad científico técnico del evento y no por la cantidad de participantes en el mismo.

\section{MESA DE BIOTECNOLOGÍA Y RECURSOS} NATURALES

\section{Integrantes del Equipo de la Mesa:}

Presidente: Ing. Aldo Rojas - Nicaragua

Secretario: Ing. Elbenes Vega - Nicaragua

Moderador y Vocal: Ing. Xenia Marín - El Salvador

\section{Número de trabajos presentados}

Total: 11

Presentados: 8

\section{Número de participantes en la Mesa}

Asistieron 12 personas en total.

\section{Número de expositores por país representados}

México (2), Nicaragua (2), Puerto Rico (1), Colombia (1), Honduras (1), Guatemala (1).

\section{Trabajos ganadores}

Primer lugar (35 puntos): Los recursos fitogenéticos en construcción: Flujo de genes y acciones de las agriculturas tradicionales. Dr. Daniel Debouck, Colombia. Centro Internacional de Agricultura Tropical (CIAT).

Segundo lugar (34 puntos): Presentación guía técnica del agua. Miguel Obando - Nicaragua. PASOLAC.

Tercer lugar (33 puntos): Identificación y dinámica poblacional de las principales plagas de pino de Nicaragua. Edgardo Jiménez - Nicaragua, Universidad Nacional Agraria (UNA).

\section{Conclusiones}

Se presentaron seis trabajos de 11 inscritos. Adicionalmente se expusieron dos trabajos más. 


\section{Recomendaciones}

a. Poner mayor énfasis en los PCCMCA a los temas de recursos naturales y biotecnología.

b. Usar mejores criterios de selección para los trabajos a discutir en esta mesa. Hubo muchos trabajos que correspondían a esta mesa y se discutieron en otras mesas.

c. Estimular más estos temas con charlas magistrales así como invitando a autoridades de los ministerios de Recursos Naturales.

\section{POSTERS}

\section{Integrantes del equipo de la mesa}

Presidente: Ing. Octavio Menocal Barberena Nicaragua

Secretario: Ing. Henner Obregón Olivas - Nicaragua Moderador y Vocal: Ing. César Estrada Rizo Nicaragua

\section{Número de posters presentados y de expositores por género:}

Total: 28 Posters

Presentados: 26 Posters

Por área o disciplina:

- Granos básicos: 17

- Hortalizas, raíces y tubérculos: 3

- Producción animal: 5

- Extensión: 2

- Caña de azúcar: 1

Por género de expositores: tres presentaciones fueron hechas por mujeres $(11 \%)$.

III. Número de participantes en la mesa: Asistieron en total 60 personas.

\section{Número de expositores por país representados}

México (17), Nicaragua (4), Puerto Rico (2), Costa Rica (2), Honduras (1), Guatemala (2).

\section{Trabajos ganadores:}

Primer lugar (25 puntos): Primer diagnóstico de resistencia a cipermetrina en Boophillus microplus parásito de bovinos en Nicaragua. Enrique Rimbaud, N. Pineda, J.L. Soto, X. Morales, Gabriela Rivera - Nicaragua. Facultad de Ciencias Agrarias, Universidad de Ciencias Comerciales (UCC), Managua.

Segundo lugar (22 puntos): Comparación de labranza convencional y labranza mínima en producción de maíz (Zea mays L.) para ensilar. Elide Valencia, Abner Rodríguez Carías, Ricardo Prieto Prieto - Puerto Rico. Departamento de Agronomía y Suelos, y Departamento de Industria Pecuniaria. Colegio de Ciencias Agrícolas. Universidad de Mayagüez, Puerto Rico.

Tercer lugar (20 puntos): Inhibición del crecimiento in vitro del micelio de Phytophthora infestans Mont de Bary por Metalaxyl y Cimoxanyl: Ing. Rafael Mora Aguilar, Miguel Angel Maldonado y Wilmer Pérez. México. Departamento de Fitotecnia. Universidad Autónoma de Chapingo, México.

\section{Mención especial}

Título: CECADER: Calidad de los Servicios para el Desarrollo Rural. María Elena Murillo Soto - México. CECADER, Estado de Coahuila. Universidad Autónoma Agraria “Antonio Narro". Buenavista, Saltillo, Coahuila, México.

\section{Conclusiones}

Se presentaron 26 posters de un total de 28 , de los cuales tres presentaciones fueron hechas por mujeres, lo cual corresponde a un $11 \%$, asistieron 60 personas.

\section{Recomendaciones}

Perfeccionar las técnicas en el diseño de los posters.

La saturación en el contenido escrito de varios de los mismos, redujo el aporte de datos significativos para la transferencia de la tecnología presentada en dichos posters. 
Incentivar la participación de mayores científicos en esta área.

\section{PROPUESTA DE REFORMA A LOS ESTATU- TOS DEL PCCMCA}

Se aprobó la propuesta de reforma a los Estatutos de la Sociedad del PCCMCA. Quedó redactado de la siguiente forma.

Aclaración: Los estatutos se aprobaron hace 16 años, y la Revista Agronomía Mesoamericana ha evolucionado hacia un medio de mayor cobertura internacional, mayor número de trabajos científicos y se ha regido recientemente con base en la reglamentación para la indización de revistas, como lo establecido por LATINDEX. Las modificaciones propuestas van orientadas a actualizar los estatutos de la Sociedad del PCCMCA, para estar acorde con la actual estrategia operativa de esta Revista.

\section{CAPÍTULO DE LAS PUBLICACIONES ARTÍCULOS 15; 16; 18; 20; 22; 23; 24 y 25.}

Artículo 15. Las personas designadas al consejo o comités de la sociedad, deben ser miembros de la Sociedad.

Artículo 16. El consejo y los comités existentes y otros comités autorizados por la junta directiva, deben constituir en lo siguiente:

a) Comité de nominaciones de una Sociedad para oficiales de Sociedades de divisiones, con el Presidente antecesor sirviendo como moderador. El número de miembros y personal que sirven en el comité será determinado por la Junta Directiva.

b) Comité de finanzas.

c) Consejo Editorial de la Revista Agronomía Mesoamericana.

d) Comité de miembros honorarios, con el Presidente antecesor como moderador.

e) Comité de estatutos y organización, con el Presidente antecesor como moderador.

Artículo 18. La Sociedad tendrá dos órganos oficiales de publicación: Compendio de resúmenes y la Revista Agronomía Mesoamericana. La publicación del compendio de resúmenes será responsabilidad del Comité Nacional Organizador de la Reunión, mientras la revista será de la Sociedad. La Revista publicará trabajos de índole científica o técnica, las actas de la Sociedad del PCCMCA y puntos de la Reunión Anual de la Junta Directiva. El Consejo Editorial será el responsable del contenido y calidad de la revista.

Artículo 20. La RevistaAgronomía Mesoamericana tendrá un Editor principal, cuatro Editores Asociados del país donde se edita la revista, un Consejo Editorial integrado por ocho miembros más, que pertenecerán a países del área centroamericana, Panamá, El Caribe y México, excepto el país donde se edita la revista, dos asistentes editoriales y un diseñador gráfico.

Artículo 22. El Consejo Editorial será propuesto por el Presidente de la Junta Directiva y avalado por la Asamblea. El nombramiento será de cinco años y podrán ser reelegidos.

Artículo 23. El Consejo Editorial coordinará la aprobación de las políticas editoriales y otras prácticas, para la Revista Agronomía Mesoamericana.

Artículo 25. La Revista podrá considerar la publicación de trabajos de índole científica o técnica escritos por profesionales que no son miembros de la Sociedad. El Consejo Editorial establecerá el monto no reembolsable a pagar por cada trabajo.

\section{NOMBRAMIENTO DE LOS EDITORES ASO- CIADOS Y CONSEJO EDITORIAL}

\section{Editores Asociados}

Carlos Araya Fernández

Carlos Boschini Figueroa

Renán Agüero Alvarado

Silvia Elena Arce Quesada

\section{Consejo Editorial}

Abelardo Viana Ruano

Juan Carlos Rosas Sotomayor

Alejandro Espinosa Calderón

Carmen Jacinto Hernández

Rogelio Lépiz Ildefonso

Freddy Alemán Zeledón 
Román Gordón Mendoza

Mildred Zapata

Se aprobó por unanimidad.

\section{PROPUESTAS PARA GESTIONAR APOYO Y PARTICIPACIÓN DE SICTA EN LA REVISTA AGRONOMÍA MESOAMERICANA Y EN LAS REUNIONES ANUALES DEL PCCMCA.}

El editor de la Revista Agronomía Mesoamericana, Ing. Rodolfo Araya Villalobos, someterá para aprobación del SICTA, un convenio SICTA/RED SICTA/ IICA/FUNDEVI-UCR, para el fortalecimiento de la publicación de esta Revista.

\section{ELECCIÓN DE NUEVA SEDE}

La Asamblea General de la LII Reunión Anual del PCCMCA designó como sede de la LIII Reunión Anual del PCCMCA-2007 a la República de Guatemala, y a su organizador: el ICTA.

\section{ASUNTOS VARIOS}

a) Se acuerda que las mesas aprobadas por la Asamblea de la Sociedad son las que están vigentes y será la asamblea la que apruebe cualquier modificación al respecto.

En esta ocasión la delegación de El Salvador presentó la solicitud de la creación de la mesa de Agroindustria, quedando pendiente de aprobación.

b) Se acuerda hacer las gestiones ante el IICA a fin de lograr su apoyo para el desarollo institucional de la Sociedad del PCCMCA.

c) Se acuerda declarar el PCCMCA como el órgano oficial del Sistema Regional de Generación y Transferencia de Tecnología. d) Se acuerda que con el propósito de fortalecer el funcionamiento de la Sociedad del PCCMCA y de sus principales mecanismos (Reunión Anual, Edición Revista Agronomía Mesoamericana, Organización y Operación de la Sociedad) cada miembro pagará \$20.00 en concepto de membresía la cual deberá ser cancelada con la cuota de inscripción en la XLIII Reunión Anual y se depositará en la Fundación de la Universidad de Costa Rica para la Investigación (FUNDEVI).

\section{CLAUSURA}

En nombre de la República de Nicaragua, el Viceministro de Agricultura, Ing. José Antonio Rivera, dio las palabras de clausura, haciendo énfasis en la perseverancia de las reuniones del PCCMCA, foro científico técnico donde los científicos investigadores del área centroamericana, Panamá, México, USA, el Caribe y los centros internacionales del CGIAR que colaboran con los programas de investigación de los países miembros de la sociedad, a que continúen presentando sus trabajos de investigación para darle la alta calidad científica de este foro internacional. Recalcó que los trabajos de investigación han generado el impacto en los sistemas productivos de los países miembros de la sociedad, el cual se observa en los aumentos de los niveles productivos del sector agrícola, economías de los países y las mejoras en la calidad de los productos agropecuarios que coadyuvan a la seguridad alimentaria y el balance nutricional de la población tanto rural como urbana de los países miembros.

Un agradecimiento del pueblo y gobierno de la república de Nicaragua a cada uno de los participantes de los países miembros que atendieron la convocatoria a la LII Reunión Anual del PCCMCA.

La Asamblea General se cerró a las 4 de la tarde el día 28 de abril de 2006. 
